\title{
A VERDADE NO NEOPRAGMATISMO DE RICHARD RORTY
}

\author{
THE TRUTH IN RICHARD RORTY'S NEOPRAGMATISM
}

\section{ADRIANO SANTOS DE OLIVEIRA ${ }^{1}$}

RESUMO: O presente trabalho tem como proposta uma apresentação e uma análise do pensamento de Richard Rorty acerca da possibilidade da noção de verdade e da mesma ser tida e abordada como objeto final da investigação filosófica. A partir da leitura da obra "Verdade e Progresso", assim como o auxílio de outras obras do respectivo autor. Em seu percurso Rorty mostra que a tentativa de se alcançar objetivamente a verdade pautada na sua relação com a ideia de real ocasiona complicações dentro da abordagem pragmatista. O papel do conhecimento, segundo Rorty, é o de proporcionar ao ser humano uma melhor vivência, tanto na sua cultura, quanto a si mesmo, sem se esquecer de uma preocupação com as gerações futuras. Para Rorty a filosofia da linguagem é o instrumento capaz de descrever as diferentes formas do mundo. O uso da linguagem está relacionado e conectado diretamente as coisas, ocasionando deste modo para o autor a sugestão de uma mudança na adoção dos vocábulos que foram apresentados pela tradição.

Palavras-chaves: Filosofia da linguagem. Pragmatismo. Verdade.

\begin{abstract}
The present work proposes a presentation and analysis of Richard Rorty1s thinking about the possibility of the notion of truth, and of it being taken and approached as the final object of philosophical investigation. From the reading "Truth and Progress", as well as the help of other works of the respective author. In his course, Rorty shows that the attempt to objectively reach the truth based on traditionally defined truth in its relation to the idea of the real, causes complications within the pragmatist approach. The role of knowledge, according to Rorty, is to provide mankind with a better experience, both for its culture and for itself, without forgetting to worry about future generations. For Rorty the philosophy of language is the instrument capable of describing the different forms of world. The use of language is directly related and connected to things, thus causing the author to suggest a change in the adoption of the words that were presented by tradition.
\end{abstract}

Keywords: Philosophy of language. Pragmatism. Truth.

\section{INTRODUÇÃO}

Tendo como base o estudo dos três primeiros capítulos do livro Verdade e Progresso (2005) de Richard Rorty, na obra o autor defende que a prática do pensamento filosófico contemporâneo instaure sobre suas atividades uma nova abordagem acerca das noções que tradicionalmente são trabalhadas, tanto na prática filosófica, quanto na científica e social, procurando assim distanciarse da visão de mundo oferecida pela modernidade. Este defende que a legitimação do conhecimento não ocorra unicamente pela relação com a ideia de 'real', mas estreite-se mais com

\footnotetext{
${ }^{1}$ Mestrando em Filosofia pela Universidade Federal do Piauí. Email: adrisanoli25@gmail.com
} 
o social, propondo assim que a autoimagem da filosofia como área do conhecimento não seja a única capaz de fornecer os critérios eficazes para a prática investigativa.

$\mathrm{Na}$ busca por encontrar os equívocos que problematizam a prática investigativa, e que concomitantemente desempenham problemáticas na busca e na formulação do conhecimento, Rorty criticará como tais atividades permaneceram até a contemporaneidade subjugadas ao crivo do ideal moderno, havendo a predominância da concepção de que a validade ou veracidade de uma prática e de suas crenças, basear-se-ia na sua relação com a natureza e na defesa da mente como a única capaz de fornecer os critérios que possibilitem o alcance da verdade, ocupando deste modo um lugar de privilégio.

Sendo, pois, com a retirada de Deus como centro do conhecimento e como aquele que proporcionaria a sua busca, a mente na modernidade ocupa o seu lugar sendo a ordenadora de todo e qualquer conhecimento. Poderíamos assim dizer que a modernidade cria um o seu "bezerro de ouro" ou o seu próprio "deus", para si, podendo a mente agora ordenar o conhecimento e designar os meios mais válidos de se investigar.

O modo de proceder da mente como tutora de praticamente quase toda a prática é designada em sua funcionalidade como um espelho que refletiria não somente a condição ou estado do ser humano, mas o estado do humano em correspondência com o estado das coisas na natureza. A problemática a qual o autor nos chama atenção é de que, as próprias práticas que se propõem a investigar a verdade ou a sua natureza não tem se ocupado em desfazerem-se da teia moderna.

Segundo Rorty “para os pragmatista o que não faz diferença na prática não possui validade para a filosofia" (2005, p.3), ao partir deste pressuposto o autor procurará esclarecer e mostrar sob que condições encontram-se as práticas intelectuais e investigativas que se propõem á uma busca objetiva da verdade. O próprio autor acusa igualmente o pragmatismo de ter se ausentado da inquirição acerca da validade das práticas do conhecimento, sendo que este assume um posicionamento de inércia diante de tais questões.

Por esta falta, segundo Rorty, verifica-se como que um abafamento de temas importantes para nossa discussão e reflexão filosófica, como a abordagem da noção de verdade o qual aqui será trabalhado. O mais importante na análise destas teorias, não são as teorias em si, mas quais as suas consequências práticas, a sua incidência em nossas ações e de como estas noções de verdade, conhecimento e razão apresentados pela modernidade, não tem dado conta o suficiente diante das exigências do atual contexto, dificultando assim o tão desejado progresso intelectual quanto cultural, ocasionando uma paralisia da cultura e da própria filosofia, e como estas noções ao n não serem 
trabalhadas sob a luz da contemporaneidade podem levar quem trata de abordá-los a adentrar a mesma circularidade discursiva da modernidade.

Rorty criticará principalmente as teorias que são tidas como portadoras da verificabilidade metodológica, autodenominando-se capazes de atingir objetivamente a verdade, ocasionando deste modo suspeitas referentes a própria abordagem da noção de verdade, onde cada uma concebe de uma forma seu real valor.

Rorty é tido por alguns filósofos como um ou o inimigo da própria filosofia, pois o interpretam como alguém que queira destruir as bases da filosofia tradicional. A pretensão do pensamento rortiano não é desconsiderar as contribuições da filosofia tradicional, mas colocar no cerne da reflexão a utilidade que estas teorias possuem perante as exigências do atual contexto, perguntando sobre até que ponto tais teorias tem sido até agora úteis para nossas discussões.

Vendo, pois que há um constante progresso da sociedade e da cultura é preciso que estes dentro do progresso que ocorre não podem estar a mercê da circularidade de discursos inférteis ou mesmo ser dependentes de (in) verdades, que somente encontram sua validade em metanarrativas, sendo que em algum momento foram refutadas tornando-se incapazes de levarem o mundo a melhorar.

\section{CRÍTICA A VERDADE COMO CORRESPONDÊNCIA}

Rorty é bastante conhecido pelo sua oposição e crítica ferrenha a noção de verdade como correspondência ao real, em seu primeiro capitulo o autor aponta a problemática relativa a não distinção correta entre justificação e verdade, apontando que comumente a validade das nossas crenças encerra-se nas justificações.

O autor aponta que o agravante do pragmatismo está em não propor uma investigação apurada sobre o tema da verdade, acabando por não trata-la de forma conveniente, pois há mais um enfoque investigativo acerca do que seja a justificação do que propriamente a verdade, ocasionando deste modo tanto uma fuga do assunto, quanto uma inversão do que se deseja conhecer.

O problema entre a justificação e a verdade gera uma limitada e equivocada abordagem acerca da noção de verdade que o pragmatismo pretende, pois sua proposta é a de fazer emergir uma nova pragmática, não mais fundada e influenciada pelo cientificismo empirista. Rorty inova no sentido de apresentar o uso da linguagem em uma perspectiva mais prática, ao qual não foi 
possível ser encontrado tão especificamente nos filósofos da filosofia analítica, chamando atenção para que o foco da análise pragmatista se volte agora mais para o campo da linguagem.

O cerne de sua crítica poder ia-se resumir na seguinte indagação: poderia ser a verdade objeto de investigação para a filosofia? Para Rorty, o uso de uma determinada ou a adoção de uma noção dentro da experiência é proporcionado pela linguagem, que combate toda tentativa de fundamentação da verdade e consequentemente a sua busca objetiva. Constatado isto, Rorty aponta que o pragmatismo possui como consequência do projeto falido da modernidade, a falta de um esclarecimento acerca da diferenciação da noção de verdade, ocasionando entre os sujeitos que aderem a uma das tradicionais teorias uma atitude de assemelhar o caminho trilhado para se chegar a verdade o mesmo da justificação.

Ocorrendo um processo de igualdade entre verdade e justificação, sendo, pois que, não se tem acesso objetivamente a verdade, mas somente a justificação, esquecendo-se da investigação da primeira, possuindo como via mais segura e mais eficaz a segunda. Cito Rorty:

\footnotetext{
Essa convicção faz com que eles suspeitem da distinção entre justificação e verdade. Pois essa diferença não tem utilidade para minhas decisões sobre o que fazer. Se tiver dúvidas concretas, específicas, acerca da verdade de uma de minhas crenças, eu posso resolvê-las, perguntando apenas se essa crença encontra-se adequadamente justificada - buscando e acessando razões adicionais a favor e contra (RORTY, 2005, p. 3)
}

Compreende-se que sobre a justificação e o seu uso, dar-se-ia em esferas mais especificas ou privadas, a qual o autor apresenta "a sua abordagem em seu uso local" (RORTY, 2005, p. 4). Nota-se que, desde a filosofia clássica há a presença de diferentes formas de justificações em nossas crenças, dotando-as de uma durabilidade (in) comum, onde há igualmente como que uma imposição de uma necessidade de que estejam em relacionadas a alguma forma de correspondência, par que daí possam ser concordantes entre si. Rorty considera esta tentativa tanto equivocada quanto frustrante, pois tentar encontrar uma linguagem-base que concilie as diferentes concepções e as tornem mais 'esclarecidas' em nenhum momento será vantajoso para a proposta do progresso relacionado às práticas.

Por este motivo o autor considera que a filosofia não seria a mais indicada a determinar sobre tais questões, pois se identifica uma tentativa de implantar o germe do realismo na linguagem, e de que ainda hoje impera sobre os debates o deter-se a tais questões, por estas serem segundo Rorty, consequências do correspondentismo. 
Ao utilizar a linguagem Rorty não nega o mundo, porém defende que nós não temos acesso ao mundo como ele é, sendo que a linguagem desempenharia o papel de ser instrumento que possibilita a aproximação de uma válida descrição do mundo, pois fazemos constantemente uso dela para falar do mundo e o descrevê-lo.

O fato de privilegiarmos uma descrição do mundo à outra não significa dizer que esta seja melhor do que aquela, pelo contrário, isto mostra que uma descrição responde mais eficazmente as exigências do atual contexto ao qual estamos inseridos, do que outra, o que não leva a desmerecer a colaboração das antigas teorias, sendo que a verdade é se não o uso de palavras que fazemos para falar das coisas.

O trabalho de Rorty é mostrar que a discussão sobre a verdade encontra na linguagem o seu auxílio pragmático, pois é possível abordá-lo visando suas consequências no campo prático da utilidade. O autor nos leva a refletir que o progresso da filosofia deva acontecer por vias de uma dissolução dos problemas tradicionais, em contrapartida, a criação de novos empregos de palavras em que as diferentes noções de verdade possam encontrar voz e vez, isto somente pode ocorrer "dentro de uma sociedade democrática" (RORTY, 1997, p. 57), onde seus falantes estejam abertos ao que seja melhor para ele e as gerações futuras, onde não se criem novas teorias sobre os mesmos velhos problemas

Como um neopragmatista Rorty colocará sempre à frente de seu pensamento a utilidade, mas tomando a devida precaução no sentido de não percorrer o mesmo caminho que alguns intelectuais tenderam a realizar, caindo no minimalismo, ou seja, falar sobre a verdade reduzindoa a justificação.

Leva-se em consideração o fato de que a diferenciação entre verdade justificação se torna problema quando a última transforma-se ou dar-se-ia a ela o critério de uma proteção a verdade, sendo que sua veracidade seria estabelecida com o real. Por mais que a justificação desempenhe importante papel, ela ainda sim é ignorada em maior crédito e valor a verdade.

\subsection{A filosofia da linguagem de Donald Davidson no pragmatismo de Rorty}

Em seu livro A Filosofia e o espelho da natureza Rorty mostra que no pensamento clássico "conhecer é representar acuradamente o que está fora da mente" (RORTY, 1994, p. 19-20). Procurando distanciar sua filosofia desta forma de pensamento, o mesmo propõe que haja o abandono das questões sobre as distinções entre aparência e realidade. Rorty defende que acerca da verdade "não há um caráter explicativo" (RORTY, 1997. p, 174), mas um "uso preventivo" (RORTY, 2005, p. 7), não encontrando no uso objetual ou semântico uma clara definição. Tal 
proposta é levada pelo pragmatista a um sentido mais 'público' poder-se-ia dizer do uso não da verdade, mas da justificação, levando assim a considerar que a justificação surge a partir de um público.

\begin{abstract}
Naquele artigo de 1986, minha ideia fundamental era a de que toda a força do uso preventivo de "verdadeiro" está em destacar que a justificação refere-se a um público e não podemos nunca excluir a possibilidade da existência de um público melhor, para o qual não seria justificável uma crença justificável para nós [...] para cada público, podemos imaginar ainda outro mais bem informado e também mais criativo - um público que possa imaginar alternativas jamais pensadas antes para a crença proposta (RORTY, 2005, p. 7)
\end{abstract}

Sendo, pois, que o sentido usual da justificação estando intrinsecamente ligado a um público, diante desta consideração poderíamos ser levados a pensar que existiriam limites na linguagem entre um público e outro, porém Rorty considera que "os limites da justificação seriam os limites da linguagem, mas a linguagem (como a imaginação) não possui limites” (RORTY, 2005, p. 7). É preciso ainda notar que ao utilizar a linguagem como instrumento capaz de diferentemente se falar do mundo, é preciso rejeitar a imagem representativa da linguagem, ou seja, a linguagem não representa o mundo. Vê-se que Rorty procura ao máximo conciliar a prática útil com a responsabilidade dos discursos emitidos por cada público.

Ao utilizar a filosofia da linguagem Rorty mostra que não temos acesso ao modo como o mundo é, sendo, pois a linguagem como instrumento possibilita se aproximar de uma válida descrição do mundo, pois fazemos constantemente uso dela para falar do mundo e o descrevê-lo.

O fato de privilegiarmos uma descrição do mundo à outra não significa dizer que esta seja melhor do que aquela, pelo contrário, isto demonstra que uma descrição responde mais eficazmente as exigências do atual contexto ao qual estamos inseridos, do que outra, o que não leva a desmerecer a colaboração das antigas teorias, sendo que a verdade é se não mais uma utilização de palavras que realizamos para falar das coisas.

O trabalho de Rorty é mostrar que a discussão sobre a verdade encontra na linguagem o seu auxílio pragmático, pois é possível abordá-lo visando suas consequências no campo prático e da utilidade. $\mathrm{O}$ autor leva-nos a refletir sobre que o progresso da filosofia deva acontecer por vias de uma dissolução dos problemas tradicionais, em contrapartida, a criação de novos empregos de palavras em que as diferentes noções da verdade possam encontrar voz e vez, isto somente pode ocorrer "dentro de uma sociedade democrática" (RORTY, 1997, p. 55), onde seus falantes estejam abertos ao que seja melhor para eles e as gerações futuras, onde não se criem novas teorias sobre os mesmos velhos problemas.

Possuindo ainda ligações com autores da filosofia analítica e da linguagem, Rorty estreita laços principalmente com Donald Davidson, pois ambos são contrários as problemáticas do realismo e correspondentismo. Este filósofo defende que a filosofia contemporânea apresenta três noções de 
verdade: a deflacionista, a epistêmica e a realista. Sendo que o mesmo rejeita todas elas, em contrapartida "quer expor uma quarta noção" (GHIRALDELLI, 2003, p.3).

Entretanto o que é apresentado aqui como proposta de Davidson é como uma versão um pouco mais liberal em relação às estas atuais noções, mostrando um reviravolta na mentalidade do autor, pois antes este as desconsiderava totalmente, sendo que o mesmo diante de alguns debates travados com Rorty, procura dar certo valor a estas teorias, pois segundo ele "cada uma das concepções tem alguma coisa a nos dizer respeito da verdade (DAVIDSON, 2000, p. 65-74)

\footnotetext{
Davidson disse uma vez que sua teoria da verdade não nos oferece nenhuma entidade com a qual comparar sentenças e que, portanto, só é uma teoria da correspondência em um sentindo despretensioso. Seu escrito Uma teoria coerentista da verdade e do conbecimento tem como slogan a expressão correspondência sem confrontação. Esse Slogan está em sintonia com seu repúdio ao que chama de dualismo de esquema e conteúdo - a ideia de que algo como a mente ou a linguagem possa ser portador de alguma relação tal como a de ajusta ou organização. (RORTY, 1997, p. 173)
}

A ideia da verdade como ajuste da realidade será uma outra problemática trabalhada por Davidson e que Rorty explorará com mais dedicação no decorrer da obra, porém não dispomos de um tempo adequado para o explorar nesta breve apresentação, mas que se dará prosseguimento no decorrer do trabalho, assim como o embate entre o Antirrealismo de Rorty e o Realismo de John Searle. Sendo que para Davidson esta noção de ajuste seria mais uma nova forma de manter o correspondentismo e o coerentismo, permanecendo e voltando-se sempre a mesma discussão infrutífera do realismo e antirrealismo.

Rorty mostra que não haveria uma verdade capaz de definir os modos comportamentais do indivíduo, o que existiria seria certo tipo de pluralidade de verdades, que somente poderiam ser notadas a partir da comunidade de agentes ou falantes. Tal forma de apresentar a verdade, fara com que Rorty seja acusado de relativista, no sentido de considerar que a falta de limites à cultura e a linguagem possibilitem os agentes de determinadas comunidades acessarem diferentes formas e tipos de linguagem.

\section{CONSIDERAÇÕES FINAIS}

Pode-se concluir neste trabalho e na análise do pensamento que Richard Rorty e seu pragmatismo que as discussões acerca de uma busca objetiva pela verdade ou um acesso imediato 
a esta, não é possível ser definida a partir de um sistema de crenças que comandam a cultura, o que ocorre na verdade é que por meio da linguagem podemos falar das coisas e descrever o mundo que ocorre por meio das justificações.

Percebeu-se durante toda a pesquisa que a proposta de Richard Rorty não é criar uma teoria da verdade e nem mesmo chegar a formular uma verdade pragmática, mas que as discussões acerca da utilidade do conhecimento devem ser centrais para as práticas investigativas, levando estas consequentemente á uma prática social que leve em consideração o melhoramento não de determinadas culturas, mas o que seja bom e melhor para as pessoas.

Rorty mostra que não há uma forma de se chegar ao que o mundo é objetivamente, o papel do conhecimento é o de proporcionar ao ser humano uma melhor vivência tanto na sua cultura quanto a si sem esquecer-se das gerações futuras. A prática social não deve estar submetida a verdade das crenças e tradições, ao contrário, estas só existem a partir das relações que são estabelecidas entre os seres, e que estão em um constante processo evolutivo.

A cultura entra em cena como o campo do uso da linguagem possibilita o acesso ao conhecimento, e a de que há existentes crenças que podem estar inseridas na adequabilidade aos padrões que a própria cultura estabelece. As implicações do questionamento de Rorty possuem grande relevância para a filosofia, ética, sociologia. Não sendo restringido á temas específicos, pois assim como defende o próprio autor, não cabe a filosofia essencialmente a mudança das nossas práticas.

\section{REFERÊNCIAS}

ARAÚJO, Inês Lacerda; CASTRO, Suzana de. Richard Rorty: filósofo da cultura. Curitiba: Champagnat, 2008.

BONDEI, Remo. A filosofia do século XX. Bauru, SP: EDUSC, 2000.

FERREIRA, Arthur Arruda L. pragmatismo e questões contemporâneas. Rio de Janeiro: Arquimedes. Grupo de Trabalho em Pragmatismo, Associação Nacional de Pós-Graduação em Filosofia, 2008.

DAVIDSON, Donald. Ensaios sobre a verdade. São Paulo: UNIMARCO, 2002.

DAVIDSON, Donald. The structure and contend of truth. The journal of Philosophy. LVXXXVII (6), 279-327, junho de 1990. 
DAVIDSON, Donald. Truth rehabilitated. In: Brandom, R. (ed) Rorty and his critics. Oxford: Blackwell, 2000.

DEWEY, John. Desenvolvimento do pragmatismo americano. Disponível em <www4.pucsp.br/pragmatismo/dowloads/3cog_est52_Dewey.pdf> Acessado em 14.10.2017

DUMMET, Mchael. Truth and other enigmas. Cambirdge: Havard University Press, 1978.

FRAGA, Marcelo l. Richard Rorty e o debate sobre a questão da verdade. Artigo. Disponível em: <esbocosfilosoficos.com/tag/Richard-rorty>. Acessado em 29.01.17

GHIRALDELLI Jr, Paulo. Davidson: a elegância no labirinto da verdade. In: DAVIDSON, Donald. Ensaios sobre a verdade. São Paulo: UNIMARCO, 2003.

Neopragmatismo e verdade: Rorty em conversação com Davidson e Habermas. São Paulo: FFLCH-USP. 2001b (tese de doutorado).

O pragmatismo e a verdade. Paulo Ghiraldelli Jr. Local: Youtube, 2012. 12:13min. Disponível em: https://youtube/CRjbYz3_JsM. Acessado em: Outubro de 2017.

HAACK, Susan. Filosofia das lógicas. São Paulo: unesp, 2002.

HOTTOIS, Gilbert. Do renascimento à pós-modernidade: uma história da filosofia moderna e contemporânea. Aparecida, SP: Ideias\&Letras, 2008.

JAMES, W. Pragmatismo. Os Pensadores. Trad. Franklin Leopoldo e Silva. James \& Bergson. São Paulo: Nova Cultural, 1989.

JAPIASSÚ, Hilton; MARCONDES, Danilo. Dicionário básico de filosofia. Jorge Zahar. Rio de Janeiro, 2001.

JOHN, Searle. Rationality and Realism: What Is a Stake?. Daedelus 122, nº 4, 1992.

KIRKHAM, Richard. Teorias da verdade. São Leopoldo: unisinos, 2003.

LALANDE, André. Vocabulário técnico e crítico da filosofia. $3^{\circ}$ ed. São Paulo: Martins Fontes, 1999.

PUTNAM, Hilary. Realism with a human face. Cambridge, Massachusetts: Havard University Press, 1990.

RORTY, Richard. A filosofia e o espelho da natureza. Rio de Janeiro: relume-Dumará, 1994. Verdade e progresso. Barueri: manolé, 2005. 
Contingência, ironia e solidariedade. São Paulo: Martins fontes, 2007.

Objetivismo, relativismo e verdade. Rio de Janeiro: Relume-Dumará, 1997.

Ensaios sobre Heidegger e outros. Rio de Janeiro: Relume-Dumará, 1999.

RORTY, Richard; GHIRALDELLI JR, Paulo. Ensaios pragmatistas: sobre subjetividade e verdade. Rio de Janeiro: DPA, 2006.

TASKI, Alfred. A concepção semântica da verdade. São Paulo: Unesp, 2007.

WEISZFLOG, Walter. Michaelis: moderno dicionário da língua portuguesa. São Paulo: Melhoramentos, 1998.

WRIGHT, Crispin. Truth and objectivity. Cambridge, Massachusetts: Havard University Press, 1992. 